Reprod. Nutr. Dévelop. 1980, 20 (2), 499-522.

\title{
Le tératocarcinome de la souris : origine et relation avec les cellules embryonnaires précoces
}

\author{
par H. CONDAMINE
}

Service de Génétique cellulaire du Collège de France ef de l'Institut Pasteur, 25 rue du Dr-Roux, 75015 Paris.

\section{Summary. Murine feratocarcinoma : Origin and relation to early embryonic cells.}

This paper reviews the origin and properties of murine teratocarcinoma stem cells as compared to early multipotential embryonic cells. Spontaneous teratomas are found in two inbred strains of mice : testicular teratomas in 129 males, ovarian teratomas in LT females. When male genital ridges or embryos from morula to egg-cylinder stages are grafted into ectopic sites, teratomas are also produced. The influence of various parameters (e.g. developmental time, site, murine strain) on the success of such grafts is described. The karyological, ultrastructural, biochemical, surface antigen and virus susceptibility properties of embryonal carcinoma cells and multipotential embryonic cells are compared. The ability of various teratocarcinoma stem cells to participate in normal embryogenesis is also compared.

This data is used to discuss the unsolved problem of identifying the cells which give rise to embryonal carcinoma and of determining the exact nature of this transformation. Two main problems are reviewed :

a) Although the various embryonal carcinoma stem cell lines isolated so far all have for instance, ultrastructural, biochemical, immunological properties in common, it is quite clear that they may, in fact, be very different from each other as to, e.g. karyotype, ability to differentiate in vifro or undergo « normalization 》 upon reinjection into a blastocyst. The question then is : do these differences reflect a drift among the cell lines, independently isolated from a unique embryonic cell type switched to a fumorigenic state, or are they at least partly due to different teratocarcinoma cell lines which may derive from different primitive embryonic cells ? The latter hypothesis assumes that some teratocarcinoma cell lines would be more similar to inner cell mass cells, while others would be equivalent to 6 or 7-day embryonic ectoderm cells. These similarities could be checked by determining the ability of embryonal carcinoma cells to interact with various multipotential embryonic cells.

b) The mechanism by which a normal embryonic cell is transformed into an embryonal carcinoma cell is quite obscure. The event(s) responsible for such a transformation may be merely epigenetic or could imply some permanent DNA modification. Although prima facie evidence does not seem to favor the latter hypothesis, it is emphasized that what is presently known of both the origin and the in vivo « normalization » of teratocarcinoma still appears to be compatible with a mutational hypothesis.

\section{Introduction.}

Les tératocarcinomes sont des tumeurs malignes que caractérise la présence, à côté d'un composant de type embryonnaire indifférencié (responsable de la malignité), de tissus différenciés éventuellement très variés, que rien ne disiingue des tissus d'un 
embryon ou d'un adulte normal, si ce n'est leur disposition apparemment anarchique. Ces dérivés différenciés ne sont en général pas tumorigènes. En revanche, l'injection d'une unique cellule indifférenciée peut aboutir à la formation d'une tumeur multidifférenciée (Kleinsmith et Pierce, 1964 ; Jami et Ritz, 1974), ce qui montre son caractère de cellule souche multipotentielle, analogue d'une cellule embryonnaire primitive. De telles tumeurs sont généralement rares chez les Mammifères. Toutefois, deux souches « inbred » de Souris onł une haute incidence de tératocarcinomes spontanés et la greffe d'un embryon hors de l'utérus, dans cerraines conditions, en provoque aussi l'apparition. A partir de ces tumeurs, des lignées cellulaires indifférenciées (carcinome embryonnaire) peuvent être isolées et entretenues in vitro. Réinjectées dans l'animal, ces lignées forment des tumeurs solides ou ascitiques. Dans ce dernier cas, on voit se développer dans la cavité péritonéale des « corps embryonnaires» typiquement composés d'un noyau de cellules indifférenciées tumorigènes entouré d'une couche de cellules identiques à celles de l'endoderme primitif (Martin, 1975). Les tumeurs solides sont soit multidifférenciées s'il s'agit de lignées multipotentielles, soit composées de carcinome embryonnaire indifférencié exclusivement : on a alors affaire à une lignée multipotentielle, qui a perdu toute aptitude à se différencier tout en gardant son pouvoir tumorigène. La différenciation de certaines lignées multipotentielles s'observe aussi in vitro (Martin et Evans, 1975 ; Nicolas et al., 1975). Enfin les cellules de certaines lignées multipotentielles peuvent être injectées dans la cavité d'un blastocyste, perdre leur caractère fumorigène et participer à une embryogenèse normale. L'ensemble de ces propriétés témoigne d'une parenfé profonde entre les cellules de carcinome embryonnaire et les cellules embryonnaires multipotentielles et a incifé un assez grand nombre de chercheurs, au cours de la dernière décennie, à étudier ce matériel tumoral, avec l'espoir d'en retirer des connaissances nouvelles sur les mécanismes de la détermination et de la différenciation cellulaires.

Une revue de l'ensemble des données expérimentales sur le tératocarcinome de la Souris qui se sont accumulées ne serait-ce qu'au cours des huit dernières années dépasserait de beaucoup l'ambition de ce travail pour lequel un point de vue particulier a éfé adopté, celui de la comparaison entre une cellule souche indifférenciée de tératocarcinome et une cellule embryonnaire précoce multipotentielle, telle qu'on en trouve dans la masse cellulaire interne du blastocyste ou dans l'ectoderme embryonnaire de l'œuf-cylindre. Fondamentalement, une cellule de tératocarcinome est-elle une cellule embryonnaire multipotentielle placée hors de son environnement normal et qui acquiert, ipso facto, ses caractéristiques fumorigènes, ou bien, pour devenir tératocarcinomateuse, une cellule embryonnaire multipotentielle doit-elle subir une ou plusieurs mutations, suivies ou non d'un processus épigénétique plus ou moins complexe ? A cette alternative, dont la formulation ici n'est pas originale (voir, par exemple, Hofnung, 1978), il ne sera pas apporté de réponse mais on a essayé de rassembler, sous trois rubriques distinctes, des faits qui peuvent aider à la solution du problème ainsi posé.

1. Une première partie concerne l'origine du tératocarcinome ef vise à préciser quelle(s) cellule(s) embryonnaire(s) peut (ou peuvent) lui donner naissance.

2. Une deuxième partie rassemble des données comparatives sur la cellule de tératocarcinome et les cellules embryonnaires précoces multipotentielles, pour voir s'il 
est possible d'identifier une cellule embryonnaire dont la cellule souche de tératocarcinome se trouverait la plus proche parente.

3. Une troisième partie traite du retour de la cellule de tératocarcinome à l'embryogenèse normale.

Chacune de ces trois parties ne fait, pour l'essentiel, que rassembler des données expérimentales. Les conclusions qu'on en peut tirer, et les problèmes qu'elles posent, seront énoncés dans une quatrième et dernière partie.

Le lecteur désireux de compléter les informations groupées ici pourra se reporter à diverses revues (Damjanov et Solter, 1974 ; Martin, 1975 ; Gachelin, 1976 ; Graham, 1977 ; Hogan, 1977 ; Jacob, 1977 ; Gachelin, 1978).

II ne sera pas fait de rappel descriptif des premiers stades de l'embryogenèse de la Souris. Le lecteur non familiarisé avec ces questions pourra consulter Theiler (1972) ou, pour un résumé succinct, la revue de Hogan (1977).

Le terme « tératocarcinome 》 désigne, comme il a été dit, des tumeurs composées de tissus différenciés non tumoraux et de carcinome embryonnaire indifférencié. Le terme « térałome» désigne des tumeurs bénignes composées de tissus différenciés exclusivement. Un tératome dérive d'un tératocarcinome par différenciation complète du carcinome embryonnaire. Le terme «tératocarcinome » sera parfois utilisé comme synonyme de «carcinome embryonnaire».

\section{I. - L'origine des tératocarcinomes murins}

\section{A. - Les tératocarcinomes spontanés.}

Chez la Souris, deux souches « inbred » ont été trouvées porteuses de tératocarcinomes avec une haute fréquence. Dans la souche 129, 1 p. 100 des mâles ont une tumeur testiculaire (Stevens et Little, 1954). Dans la souche LT, la moitié des femelles portait un tératome ovarien (Stevens et Varnum, 1974). Dans aucun de ces deux cas le déterminisme génétique responsable de cette haute incidence tumorale n'est connu. Toutefois parmi 15 lignées recombinantes « inbred 》 formées à partir des lignées 129 et $\mathrm{C} 57 \mathrm{BL} / 6$, une lignée a été retrouvée porteuse de ce caractère. Ce taux de ségrégation est compatible avec un déterminisme génétique assez simple, dans lequel 3 ou 4 gènes au plus gouverneraient l'apparition des fumeurs (J. L. Guénet, communication personnelle). Par ailleurs certaines mutations introduites dans la souche 129 modifient le faux spontané de tératomes, soit pour l'abaisser (cas de l'allèle « yellow » de la série A, Stevens 1967a) ou pour l'élever (cas de la mutation Steel, Stevens et Mackensen, 1961). II est à noter que la mutation Steel est connue pour modifier l'environnement nécessaire au développement normal de la lignée érythropoiétique (Mintz et Cronmiller, 1978). On peut supposer, mais il n'esł pas prouvé, qu'elle contribue de même à modifier l'environnement nécessaire au développement normal de la lignée germinale, cible de la transformation tératocarcinomateuse (voir plus bas). En outre, à partir de la lignée 129, une sous-lignée, différente de la précédente par un petit nombre de gènes, peut-être un seul, a été établie, chez laquelle près de 30 p. 100 des mâles portent un tératome testiculaire spontané (souche 129/ter Sv ; Stevens, 1973). 
L'origine des tératomes dans la souche 129 peut être ramenée à un événement qui affecte l'embryon vers le deuxième tiers de la vie embryonnaire. En effet, l'incidence de tératocarcinomes est aussi élevée chez les foetus que chez les adultes de la souche 129 (Stevens, 1959) et des tumeurs, composées alors de petits agrégats de cellules indifférenciées enclos à l'intérieur des tubes séminifères des testicules embryonnaires, sont repérables dès le jour 15 de la gestation (Stevens, 1962).

L'origine des tératomes ovariens dans la souche LT sera examinée après l'exposé de techniques qui permettent l'obtention de tératomes provoqués.

\section{B. - Tératocarcinomes provoqués par la greffe de crêtes génitales mâles.}

La courbe qui retrace l'évolution de la taille des tératomes (déterminée par le nombre de coupes histologiques sériées sur lesquelles un tératome est visible) en fonction de l'âge de l'embryon s'extrapole, pour une taille nulle, vers le jour 12 de l'embryogenèse (Stevens, 1962). C'est donc à ce moment qu'on doit supposer quelque événement critique qui déclenche la tumorigenèse. Ceci a conduit Stevens à tenter la greffe de crêtes génitales d'embryons âgés de 12 jours en divers organes d'un receveur adulte. 82 p. 100 des crêtes génitales mâles de foetus 129 de 12 jours greffés dans un testicule développent des fumeurs. L'examen histologique du greffon pratiqué au bout d'une dizaine de jours révèle la présence de nombreux foyers (10 à 20) tératomateux indépendants (Stevens, 1964). Des crêtes génitales mâles de 13 jours greffées dans les mêmes conditions ne fournissent plus que 9 p. 100 de tératomes. La greffe pratiquée au jour 12 mais ailleurs que dans le testicule (foie, rein, rate, ...) s'avère inefficace : le greffon s'organise en testicule normal, dépourvu de tumeur (de même, les crêtes génitales femelles évoluent en un tissu ovarien normal, quels que soient le moment ef le site de la greffe). Pourtant, l'environnement testiculaire n'est pas indispensable à l'apparition de tératomes dans une greffe mâle de 12 jours : il suffit que la greffe soit effectuée dans un organe apte à descendre dans le scrotum (épididyme, coussin graisseux de l'épididyme) d'un animal qui peut avoir été castré sans que le succès de la tératogenèse soit compromis : les hormones testiculaires ne sont donc pas nécessaires. II semble bien que la température relativement basse du scrotum soit le facteur décisif qui déclenche la prolifération tumorale dans les crêtes génitales mâles de 12 jours. Cette prolifération affecte spécifiquement les cellules germinales primordiales, non les cellules somatiques de la crête génitale : des crêtes mâles d'embryons 129 de 12 jours, mais homozygotes pour la mutation Steel, ef par conséquent dépourvues de cellules germinales, ne fournissent pas de tératomes, alors que les tissus somatiques de ces gonades sont normaux (Stevens, 1967b). L'aptitude à donner des tératomes chez des crêtes génitales provenant d'embryons de souches variées a été quelque peu explorée. Des greffes de crêtes génifales de la souche $\mathrm{A} / \mathrm{He}$ sont tératogènes (Stevens, 1970a) au contraire de greffes de crêtes génitales $\mathrm{C} 3 \mathrm{H}$ ou DBA/1 (Stevens, 1964). Dans chacune de ces 3 souches, l'incidence de tératomes spontanés est à peu près nulle. Par ailleurs, à la différence de la souche 129, c'est dans un embryon $\mathrm{A} / \mathrm{He}$ âgé de 13 jours qu'on trouve l'aptitude maximale à la tératogenèse. Des greffes de crêtes génitales hybrides $A \times 129$ fournissent aussi des tératomes, avec une efficacité voisine de 100 p. 100, que la greffe soit pratiquée au jour 12 ou au jour 13 de l'embryogenèse. Il semble que les greffes (non tératogènes) de crêtes $\mathrm{C} 3 \mathrm{H}$ ou $\mathrm{DBA} / 1$ 
aient été pratiquées au seul jour 12. On peut donc se demander si, pratiquées à un autre moment, elles n'auraient pas eu la même efficacité que des greffes de crêtes génitales 129 de 12 jours ou A/He de 13 jours.

On a vu plus haut que dans une greffe de crête génitale d'embryon 129 âgé de 12 jours, 10 à 20 foyers tératomateux pouvaient être repérés. Le nombre de cellules germinales primordiales dans des embryons C57BL/6 du même âge s'élève à quelques milliers (Mintz et Russell, 1957). On peut donc estimer à 1 p. 100 environ la fréquence cellulaire de l'événement qui, dans une telle greffe, aboutit à faire d'une cellule germinale primordiale une cellule de carcinome embryonnaire. Il se peut que la stimulation (liée apparemment à un abaissement de la température) apportée par la greffe ne soit efficace que sur des cellules de génotypes particuliers (A ou 129). Mais cela ne paraît pas vraiment démontré ef peut-être toute cellule germinale primordiale de souris traverse-t-elle une phase critique aux environs du jour 12 de l'embryogenèse, au cours de laquelle elle peut être transformée en cellule tumorale. Rien n'est actuellement connu du mécanisme de cette rransformation.

\section{C. - Tératocarcinomes provoqués par la greffe d'embryons.}

Une autre manière d'obtenir des tératomes consiste à greffer des embryons, pris à des stades précoces du développement, en différents sites extra-utérins, sous la capsule testiculaire ou rénale ou dans la chambre antérieure de l'œil (voir la revue de Damjanov et Solter, 1974). Des expériences réalisées par divers auteurs au cours des 10 dernières années, les principales conclusions tirées sont les suivantes.

La greffe d'embryons très jeunes (stade 2 cellules) donne surtout naissance à des dérivés trophoblastiques. En revanche, pris au stade blastocyste (embryons de 3 jours) ou, après leur implantation dans l'utérus, au stade de l'œuf-cylindre (embryons de 6 et 7 jours), mais pas au-delà, les embryons greffés donnent avec une haute efficacité des tumeurs où des dérivés différenciés très variés voisinent éventuellement avec des cellules indifférenciées, que rien ne distingue des carcinomes embryonnaires d'origine spontanée, et à partir desquelles des souches de tératocarcinomes transplantables ont pu être obtenues. L'aptitude des embryons greffés à donner des tumeurs différenciées ne semble pas dépendre de leur génotype. Les principales souches utilisées sont les souches 129 ou A/He (Stevens, 1970b), C3H (Solter, Skreb et Damjanov, 1970), C57BL/6, AKR (Solter, Damjanov et Koprowski, 1975) et parfois des souches hybrides (F1 Rb7 $\times$ 129) (Kelly, Guénet et Condamine, 1979). En revanche, la présence d'un composant tératocarcinomateux (malin) au sein des tumeurs différenciées dépend beaucoup du système expérimental utilisé : des embryons $\mathrm{C} 3 \mathrm{H}$ greffés dans un hôte $\mathrm{C} 3 \mathrm{H}$ fournissent des tumeurs à haute fréquence de carcinome embryonnaire. Des embryons $\mathrm{C} 57 \mathrm{BL} / 6$ greffés dans un hôte $\mathrm{C} 57 \mathrm{BL} / 6$ donnent des tumeurs presque exclusivement bénignes, dépourvues de carcinome embryonnaire. Les causes de cette différence ne sont pas connues avec précision, mais on peut soupçonner que le système immunitaire y joue quelque rôle. D'une part, la splénectomie élimine à peu près la formation de tumeurs dans la souche C57BL/6 ef inhibe fortement la croissance des tumeurs $\mathrm{C} 3 \mathrm{H}$. D'autre part, des embryons $\mathrm{C} 57 \mathrm{BL} / 6$ greffés dans un hybride $\mathrm{C} 3 \mathrm{H} \times$ C57BL/6 fournissent des fumeurs tératocarcinomateuses retransplantables dans le même hybride mais non dans le parent C57BL/6 (Solter, Damjanov et Koprowski, 
1975), ef ceci montre que dans une souche qui ne donne pas de carcinome embryonnaire dans les conditions usuelles (greffe syngénique d'un embryon), l'embryon luimême n'est pas en cause mais plutôt son environnement. En outre, la greffe d'un embryon $\mathrm{C} 3 \mathrm{H}$ dans une souris $\mathrm{C} 3 \mathrm{H}$ thymectomisée ou dans une souris nude donne aussi des tumeurs réduites et dépourvues de tératocarcinome dans la majorité des cas (Solter et Damjanov, 1979). L'importance du système immunitaire dans la facilitation ou l'inhibition de la croissance du tératocarcinome est enfin illustrée par des expériences effectuées cette fois sur des lignées établies in vitro. L'intervention d'un petit nombre de facteurs génétiques récessifs qui contrôlent la croissance du tératocarcinome dans des hôtes allogéniques a été établie par Avner et al. (1978). Par ailleurs, l'emploi de mutagènes a permis l'obtention de variants de lignées tératocarcinomateuses incapables de croître dans un hôte syngénique, à moins que celui-ci n'ait été irradié. Les tumeurs formées dans ce dernier cas offrent une variété de tissus différenciés qui montrent que les variants n'ont rien perdu de leur caractère multipotentiel (Boon et Kellermann, 1977 ; Boon et Van Pel, 1978). Rapprochés des observations de Solter, Damjanov et Koprowski citées plus haut, ces faits constituent une bonne illustration de la théorie de Prehn (1977) qui postule un équilibre complexe entre stimulation et inhibition de la croissance des cellules tumorales sous l'action du système immunitaire.

Une différence critique sépare, du point de vue qui nous occupe, un embryon de 7 jours d'un embryon de 8 jours : le premier peut donner des tumeurs tératocarcinomateuses, le second ne donne jamais que des tumeurs bénignes complètement différenciées. Il paraît assez clair que cette différence tient à la présence dans l'embryon de 7 jours d'un feuillet improprement appelé ectoderme embryonnaire, en fait indifférencié (peut-être totipotent) et qui n'existe plus dans l'embryon de 8 jours où il a donné naissance à l'ectoderme proprement dit et au mésoderme. Chez l'embryon de 6 ou 7 jours, ce feuillet peut être séparé de l'endoderme et il est seul capable de donner naissance, après greffe dans un testicule, à des tératocarcinomes multidifférenciés. L'endoderme, greffé, ne se développe pas. L'ectoderme extra-embryonnaire ne fournit, lui, que des dérivés trophoblastiques (Diwan et Stevens, 1976).

Rien ne permet de dire à l'heure actuelle si dans un embryon de 6 ou 7 jours toutes les cellules de « l'ectoderme embryonnaire » ont la même probabilité de subir la transition vers l'état tératocarcinomateux après que l'embryon a été greffé en un site extra-utérin. II ne semble pas qu'on ait jamais décrit des différenciations qui opposeraient certains types de cellules à d'autres à l'intérieur de ce feuillet, plutôt considéré comme totipotent dans son ensemble. En particulier, les cellules germinales primordiales ne commencent à être repérées que dans un embryon de 9 jours, au niveau du sac vitellin (Mintz et Russell, 1957). En fait, il est avéré que des embryons de 6 jours, homozygotes pour les mutations Steel ou W qui empêchent l'une et l'autre le développement des cellules germinales, fournissent, après greffe, des tératocarcinomes avec une efficacité comparable à celle d'embryons témoins, non mutants (Mintz, Cronmiller et Custer, 1978). Ceci indique peut-être que dans l'œuf-cylindre, la distinction entre cellules germinales et somatiques n'est pas encore opérée, ou bien on peut faire I'hypothèse, retenue par Mintz et ses collaborateurs, que les tératocarcinomes ont dans l'embryon une origine exclusivement somatique.

Il convient de mentionner ici le cas de la souche LT dont on a vu plus haut qu'elle 
comportait une haute incidence de tératomes ovariens spontanés. Toutefois, la caractéristique première de cette souche semble la haute fréquence d'activation spontanée de ses ovocytes. Il en résulte le développement de nombreux embryons parthénogénétiques dont certains évoluent en blastocystes, voire en œufs-cylindres typiques (Stevens ef Varnum, 1974). Cela constitue une expérience naturelle de greffe d'embryons, ef c'est à partir de ceux-ci que se développent des tératomes doni un petit nombre comporte du carcinome embryonnaire. Il a été montré que l'acíivation parthénogénétique qui précède la formation des tératomes LT affecte des cellules qui ont subi la réduction méiotique. En effet, dans un hôte hétérozygote pour un marqueur enzymatique donné, les tumeurs trouvées sont homozygotes pour l'un ou l'autre allèle du marqueur considéré (Eppig et al., 1977). Le mécanisme par lequel les cellules parthénogénétiques se rediploïdisent ensuite n'est pas connu, mais ce point distingue les tératomes LT des tératomes testiculaires spontanés ou de ceux provoqués par la greffe d'embryons : dans ces deux cas, on peut obtenir des tératomes mâles de constitution $X Y$ qui, par conséquent, ne sauraient provenir d'une lignée ayant subi la réduction chromatique.

\section{D. - Conclusions.}

Le tableau 1 résume l'ensemble des données qui viennent d'être exposées. II existe à l'heure actuelle 4 façons d'obtenir des tumeurs tératomateuses d'origine soit spontanée, soit expérimentale. La proportion de carcinome embryonnaire présent dans ces tumeurs varie selon les cas. Plus cette proportion est élevée, et plus il y a de chance d'extraire de la tumeur une lignée indifférenciée retransplantable in vivo et

\section{TABLEAU 1}

Mades d'obtention du tératocarcinome chez la Souris

\begin{tabular}{|c|c|c|c|c|}
\hline Origine & \multicolumn{2}{|c|}{ Organe } & $\begin{array}{c}\text { Cellules (ou tissu) cibles de la } \\
\text { transformation } \\
\text { tératocarcinomateuse }\end{array}$ & $\begin{array}{l}\text { Présence de } \\
\text { carcinome } \\
\text { embryonnaire }\end{array}$ \\
\hline Spontanée & \multicolumn{2}{|c|}{$\begin{array}{ll}\text { Testicule } & \\
\quad \text { souche } 129 / \mathrm{Sr} & (10 \text { p. } 100) \\
\quad \text { souche } 129 / \mathrm{Ter} & (30 \text { p. } 100) \\
\begin{array}{l}\text { Ovaire } \\
\text { souche LT }\end{array} & (50 \text { p. } 100)\end{array}$} & $\begin{array}{l}\text { Cellules germinales de l'em- } \\
\text { bryon de } 12 \text { jours } \\
\text { Ectoderme embryonnaire d'em- } \\
\text { bryons parthénogénétiques }\end{array}$ & $\begin{array}{l}\text { fréquente } \\
\text { assez rare }\end{array}$ \\
\hline $\begin{array}{l}\text { Provoquée } \\
\text { a) par greffe intra- } \\
\text { testiculaire }\end{array}$ & \multirow{2}{*}{\multicolumn{2}{|c|}{$\begin{array}{l}\text { Crêtes génitales d'embryons mâ- } \\
\text { les } \\
\text { de } 12 \text { jours (souche } 129 / \mathrm{Sv} \text { ) } \\
\text { de } 13 \text { jours (souche } \mathrm{A} / \mathrm{He} \text { ) } \\
\text { de } 12 \text { ou } 13 \text { jours }\left(\mathrm{F}_{1} 129 \times \mathrm{A}\right) \\
\text { Embryons de } 3 \text { à } 7 \text { jours } \\
\text { souche } 129 \\
- \text { C } 3 \mathrm{H} \\
- \text { C } 57 \mathrm{BL} / 6 \\
- \text { AKR }\end{array}$}} & & \\
\hline $\begin{array}{l}\text { b) par greffe intra- } \\
\text { testiculaire ou } \\
\text { sous la capsule } \\
\text { rénale }\end{array}$ & & & $\begin{array}{l}\text { Cellules germinales } \\
\text { Cellules germinales } \\
\text { Cellules germinales } \\
\text { Ectoderme embryonnaire } \\
\text { Ectoderme embryonnaire } \\
\text { Ectoderme embryonnaire } \\
\text { Ectoderme embryonnaire }\end{array}$ & $\begin{array}{l}\text { fréquente } \\
\text { fréquente } \\
\text { fréquente } \\
\text { fréquente } \\
\text { fréquente } \\
\text { très rare } \\
\text { très rare }\end{array}$ \\
\hline
\end{tabular}


qu'on puisse entretenir in vitro. Des 4 modes d'obtention de fératomes murins, aucun ne fait appel à un système expérimental qui se déroulerait purement in vitro. La mise au point d'un tel système serait cerfainement d'un grand intérêt et devrait permettre de préciser les facteurs qui influent sur la transition d'une cellule embryonnaire à une cellule tératocarcinomateuse. A première vue, l'examen du tableau 1 fait penser que le tératocarcinome a plusieurs origines possible (cellule germinale mâle de 12 ou 13 jours, cellule d'ectoderme embryonnaire de 6 jours...). La question de savoir si cette apparente diversité ne masque pas un unique type d'événement cellulaire sera discutée plus loin.

\section{II. - Propriétés comparées des cellules embryonnaires multipotentielles et des cellules de tératocarcinome}

Dans cette deuxième partie, les cellules embryonnaires et les cellules de tératocarcinome seront comparées, du point de vue de leurs propriétés structurales, biochimiques, immunologiques ou physiologiques.

\section{A. - Caryologie.}

Un caractère frappant des lignées de tératocarcinome est leur constitution caryologique foujours très voisine de la diploïdie normale. A l'examen détaillé la diploīdie vraie est toutefois très rare (Cronmiller et Mintz, 1978) et des trisomies ou de petifes délétions sont communes (McBurney, 1976 ; Nicolas et al., 1976 ; lles et Evans, 1977). Ces anomalies mineures semblent se produire au hasard et aucune ne paraît liée ni à l'état tératocarcinomateux, ni aux propriétés de différenciation des lignées. En revanche, la différenciation s'accompagne souvent de l'acquisition de la quasitétraploïdie (Swartzendruber, Scott Cram et Lehmann, 1976).

On sait que dans les cellules femelles de Mammifères, l'un des deux chromosomes $X$ est inactivé très tôt au cours de l'embryogenèse (voir la revue de Gartler et Andina, 1976), à peu près au moment de l'implantation du blastocyste dans la paroi de l'utérus. Il éfait donc intéressant de rechercher ce qu'il en était dans le cas des lignées de tératocarcinome femelle. Une étude de McBurney et Adamson (1976) sur de telle lignées indique que, selon plusieurs critères, l'inactivation a déjà eu lieu (à l'exception possible d'une lignée où l'inactivation serait partielle). En revanche, des indications très convaincantes que, dans d'autres souches provenant d'une tumeur LT spontanée, les deux chromosomes $X$ sont fonctionnels ont été fournies par Martin et al. (1978). Dans ce dernier cas, la différenciation in vitro des cellules souches s'accompagne de l'inactivation de l'un des deux chromosomes $X$, comme au cours de l'embryogenèse normale.

On voit donc par ces résultats opposés qu'il convient de ne pas envisager la cellule de tératocarcinome comme une entité unique et immuable. Des lignées tératocarcinomateuses différentes, qu'elles aient été isolées à partir de la même tumeur initiale ou non, ont chacune leur histoire au cours de laquelle, sans perdre leur caractère de cellule souche indifférenciée et multipotentielle, elles ont pu acquérir chacune leurs caractéristiques propres. 
Les souches de tératocarcinome femelle où les deux chromosomes $X$ sont actifs apparaissent, de par ce caractère, proches de cellules embryonnaires très précoces, par exemple celles de la masse cellulaire interne.

\section{B. - Ultrastructure.}

Le tableau 2 résume les principaux résultats concernant l'ultrastructure des cellules germinales primordiales, des cellules embryonnaires précoces ef des cellules souches de tératocarcinome (Pierce et Beals, 1964 ; Calarco ef Brown, 1969 ; Spiegelman et Bennett, 1973 ; Solter et al., 1974, Damjanov, Katic et Stevens, 1975 ; Damjanov $\in$ t Solter, 1975). Toutes ces cellules paraissent posséder une grande quantité de ribosomes libres éventuellement groupés en polysomes, mais très peu de réticulum endoplasmique organisé. De même, la relative pauvreté en structures de Golgi bien développées, la présence de particules de type A sont des traits communs. Les différences les plus saillantes portent sur des inclusions cytoplasmiques (matériel cristalloïde associé aux mitochondries) ou nucléaires (« intranuclear annulate lamellae ») présentes, les unes et les autres, dans les cellules de morulas ou blastocystes mais non dans le tératocarcinome, l'ectoderme embryonnaire, ou les cellules germinales primordiales. La similitude ultrastructurale de ces trois derniers types cellulaires a donc été soulignée (Damjanov et Solter, 1974, 1975).

\section{TABLEAU 2}

Ulirastructure des cellules embryonnaires précoces et du carcinome embryonnaire

\begin{tabular}{|c|c|c|c|c|c|c|c|}
\hline \multirow[b]{2}{*}{ Cellule } & \multirow{2}{*}{$\begin{array}{l}\text { Ribosomes } \\
\text { libres } \\
\text { (polysomes) }\end{array}$} & \multirow{2}{*}{$\begin{array}{l}\text { Reticulum } \\
\text { endo- } \\
\text { plasmique }\end{array}$} & \multirow[b]{2}{*}{$\begin{array}{l}\text { Mitochon- } \\
\text { dries }\end{array}$} & \multirow[b]{2}{*}{$\begin{array}{l}\text { Appareil } \\
\text { de Golgi }\end{array}$} & \multicolumn{2}{|c|}{ Noyau } & \multirow{2}{*}{$\begin{array}{l}\text { Parti- } \\
\text { cules } \\
\text { virales }\end{array}$} \\
\hline & & & & & $\begin{array}{l}\text { Rapport } \\
\text { nucléo- } \\
\text { plasmique }\end{array}$ & $\operatorname{IAL}(a)$ & \\
\hline $\begin{array}{c}\text { Cellules germi- } \\
\text { nales (gona- } \\
\text { des embryon- } \\
\text { naires) ...... }\end{array}$ & +++ & \pm & $\begin{array}{l}\text { Petites, } \\
\text { Ovales }\end{array}$ & -++ & Elevé & - & - \\
\hline Morula ....... & $+t+$ & \pm & $\begin{array}{c}\text { Cylindriques } \\
\text { vacuolisées }\end{array}$ & \pm & 一 & Fréquentes & type A \\
\hline $\begin{array}{l}\text { Blastocyste } \\
\text { (Masse cellu- } \\
\text { laire interne). }\end{array}$ & $+t+$ & \pm & $\begin{array}{c}\text { Cylindriques } \\
\text { vacuolisées }\end{array}$ & \pm & - & $\begin{array}{l}\text { Occasion- } \\
\text { nelles }\end{array}$ & - \\
\hline $\begin{array}{c}\text { Ectoderme em- } \\
\text { bryonnaire .. }\end{array}$ & +++ & \pm & Rares & Rare & Elevé & Absentes & type A \\
\hline $\begin{array}{c}\text { Carcinome em- } \\
\text { bryonnaire . }\end{array}$ & +++ & \pm & $\begin{array}{l}\text { Petites, } \\
\text { rondes } \\
\text { ou ovales }\end{array}$ & + & Elevé & Absentes & type A \\
\hline
\end{tabular}

(a) "Intranuclear annulate lamellae » ; cf. Calarco et Brown (1969). 
Des techniques d'immunofluorescence indirecte ont permis récemment l'étude du cytosquelette de certaines lignées de tératocarcinomes (Paulin ef al., 1978). L'actine y a été trouvée dispersée à l'état monomérique, alors que, dans des cellules différenciées dérivées de tératocarcinome, elle est disposée en « câbles 》 hautement polymérisés. Un résultat semblable a été obtenu avec l'embryon de 3 jours (stade blastocyste) : l'actine est à l'état monomérique dans les cellules (totipotentielles) de la masse cellulaire interne, et hautement polymérisée dans les cellules (différenciées) du trophectoderme (D. Paulin, communication personnelle).

\section{C. - Marqueurs biochimiques.}

Un très grand nombre d'études consacrées au tératocarcinome au cours des dernières années consistent à suivre l'évolution d'un ou plusieurs marqueurs biochimiques au fur et à mesure de la différenciation in vivo ou in vifro, de la lignée multipotentielle. On ne s'attachera ici qu'à la considération des travaux en nombre beaucoup plus réduit, qui s'efforcent de retrouver dans l'embryogenèse normale la situation observée chez le tératocarcinome (ou l'inverse). Des références complémentaires pourront être trouvées dans les revues citées au début de cet article.

1) Protéines totales de l'embryon et du tératocarcinome.

La technique d'électrophorèse à deux dimensions des protéines, due à O'Farrell (1975), a permis, depuis quelques années, la recherche de différences entre diverses lignées cellulaires, portant sur un nombre de protéines considérablement accru. En outre, la sensibilité des techniques de marquage radioactif permet de rechercher ces différences sur un matériel cellulaire relativement réduit, en sorte qu'un pool de quelques dizaines d'embryons pris à un stade anférieur à l'implantation peut permettre d'effectuer une expérience. Une des premières applications de cette technique à l'étude de la différenciation de la morula de la souris en blastocystes est due à Van Blerkom, Barton et Johnson (1976), qui ont pu repérer des polypeptides spécifiques du trophoblaste ou de la masse cellulaire interne. De même, Handyside et Johnson (1978) ef Levinson ef al. (1978) se sont attachés à déceler des protéines spécifiques de certains stades de l'embryogenèse entre la formation de l'œuf et celle du blastocyste. La comparaison effective entre embryons précoces et cellules de tératocarcinome a été réalisée par Dewey, Filler et Mintz (1978). Aucun des stades embryonnaires (tous antérieurs à l'implantation) examinés par ces auteurs n'a livré une grille de protéines strictement identique à la grille obtenue à partir de corps embryonnaires de tératocarcinome. Les différences observées, minimes, n'étaient pourtant pas nécessairement le signe d'états distincts de différenciation : des embryons pris au même stade ınais préparés de façons différentes fournissent éventuellement quelques taches différentes. II est clair que des comparaisons supplémentaires (avec des embryons déjà implantés par exemple) sont nécessaires mais ce résultat, énigmatique, indique aussi la prudence qu'on doit y apporter. II serait intéressant également de reprendre par cette technique une étude de Martin, Smith ef Epstein (1978) où les protéines du tératocarcinome et de l'embryon avaient été comparées après électrophorèse à une dimension. Pour l'essentiel, aucune différence n'étaił observée entre le tératocarcinome eł 
l'ectoderme embryonnaire du blastocyste, défini comme le massif cellulaire obtenu par traitement immunochirurgical (qui dissout la couche périphérique d'endoderme) de la masse cellulaire interne.

2) Glycopeptides du tératocarcinome et de l'embryon.

Muramatsu ef al. (1978) ont cherché à caractériser les glycopeptides résultant de la digestion prolongée des cellules de tératocarcinome par la pronase. Chromatographié sur une colonne de Sephadex G50, l'hydrolysat fournit deux pics d'élution dont l'un est remarquable en ce qu'il correspond à une famille de composés d'assez haut poids moléculaire (environ 6000 daltons) riche en fucose et galactose et qui ne semble pas avoir d'équivalent connu dans les cellules différenciées. Le deuxième pic correspond à un matériel de plus faible poids moléculaire (environ 2000 daltons) riche en mannose, qui se retrouve dans les cellules adultes différenciées. Le matériel de haut poids moléculaire est situé en surface au moins pour partie et il a été retrouvé chez l'embryon, dès le stade morula. Après l'implantation, son importance décroît progressivement et il disparaît aux environs du jour 8, moment où les cellules de l'ectoderme embryonnaire perdent leur totipotence (Muramatsu ef al., 1979). La fonction de ces glycopeptides n'est pas connue mais il paraît assez clair que leur présence est liée à l'état indifférencié multipotentiel chez l'embryon comme dans les cellules de tératocarcinome. Ils pourraient faire partie du groupe d'antigènes F9 (Gachelin et Muramatsu, communication personnelle) dont la chronologie de disparition au cours de l'embryogenèse est du reste voisine (voir plus bas). Ces résultats sont en outre à rapprocher de ceux de Gachelin et al. (1976a) qui montrent que la différenciation des cellules de tératocarcinome s'accompagne de changements dans la densité de répartition en surface des récepteurs de certaines lectines, celle extraite du Lotus tetragonolobus notamment, qui reconnaît spécifiquement le fucose. Toutefois, dans ce dernier cas, les données correspondantes pour l'embryon manquent.

\section{3) Marqueurs enzymatiques.}

On connaît très peu d'enzymes caractéristiques des cellules indifférenciées de tératocarcinome et de l'embryon. L'une des plus étudiées est la phosphatase alcaline dont on connaît plusieurs isoenzymes. La présence d'une activité phosphatase alcaline dans les cellules souches de tératocarcinome, son absence dans les cellules différenciées qui en dérivent, ont été vérifiées à plusieurs reprises (Bernstine et al., 1973 ; Martin et Evans, 1975). Clairement distincte des isoenzymes du foie et de l'intestin, l'isoenzyme du tératocarcinome se sépare aussi en électrophorèse sur gel de polyacrylamide, des isoenzymes du rein et du placenta, dont ses propriétés d'inactivation thermique la rapprochent pourtant (Wada et al., 1976). Toutefois, une étude récente de Hass et al. (1979) a révélé que les différences entre phosphatases alcalines du tératocarcinome, du rein ef du placenta sont abolies après trailement à la neuraminidase et il apparaît qu'il s'agit, dans tous les cas, d'une même protéine, glycosylée d'une façon spécifique pour chaque tissu. Les isoenzymes responsables de l'activité phosphatase alcaline dans l'embryon précoce n'ont pas été caractérisées d'une façon aussi précise. Mais l'histochimie du blastocyste révèle une situation très semblable à celle offerte par le tératocarcinome : haute activité dans les cellules totipotentes de la 
masse cellulaire interne, activité faible ou nulle dans les cellules de l'endoderme primitif qui en dérive (Damjanov et Solter, 1975).

L'histochimie comparée de deux autres activités enzymatiques a été effectuée par Damjanov, Cutler et Solter (1977). Dans ce cas, les cellules de tératocarcinome et d'embryons de 6 à 8 jours présentent des différences marquées. Une intense activité 5 '-nucléotidase est présente chez les premières, absente chez les secondes. De même, les cellules de tératocarcinomes sont riches d'une activité ATPase qu'on ne trouve qu'occasionnellement chez les embryons de 7 ou 8 jours. On possède des renseignements sur les formes d'isoenzymes présentes dans les cellules de tératocarcinome, pour certaines enzymes oligomériques dont on connaît plusieurs types de sous-unités qui apparaissent de façon spécifique au cours de la différenciation de certains organes: l'énolase (Fletcher ef al., 1978), la créatine phosphokinase, l'aldolase ef la phosphoglycérate mutase (Adamson, 1976). Dans tous ces cas, la forme présente chez le tératocarcinome est la forme trouvée de façon exclusive ou prédominante chez les embryons les plus précoces examinés, à savoir des embryons de 10 jours. Bien qu'à ce stade il ne subsiste d'autres cellules totipotentes que celles de la lignée germinale, on peut supposer qu'aucune transition isoenzymatique n'a encore eu lieu et que l'ectoderme embryonnaire des jours 6 ef 7 auraił par conséquent la même isoenzyme que le tératocarcinome.

Enfin, Soriano ef Paulin (1978) ont récemment montré que les cellules indifférenciées de tératocarcinome sont très riches en Deoxyribonucléase I, alors que les lignées différenciées qui en dérivent contiennent 20 à 30 fois moins de cette activité. II sera intéressant de voir ce qu'il en est dans les cellules embryonnaires précoces.

\section{D. - Antigènes de surface.}

Les lignées de tératocarcinome ont permis l'obtention, au cours des dernières années, de foute une série d'antisérums d’origine variée, xénogénique, allogénique ou syngénique. Ces différents sérums ont des propriétés qui varient en fonction du producteur d'anticorps mais aussi de l'immunogène utilisé. II n'en sera pas fait ici une revue détaillée, pour laquelle on se reportera à Jacob (1977) et à Gachelin (1978). Nous nous bornerons à rappeler les propriétés de deux sérums syngéniques dirigés contre les lignées F9 et PCC4, celles d'un sérum xénogénique anti-F9 et le problème soulevé par les antigènes $\mathrm{H}-2$.

\section{1) Sérum syngénique anti-F9.}

La lignée F9 est indifférenciée, tumorigène dans la souris 129 d'où elle tire son origine mais à peu près nullipotentielle : les tumeurs qu'elle forme sont quasi dépourvues de composants différenciés, à l'exception d'un peu d'endoderme (Sherman et Miller, 1978). L'hyperimmunisation de souris 129 contre cette lignée fournit un sérum syngénique très actif, à la fois en cyłotoxicité et en immunofluorescence indirecte, contre toutes les lignées de tératocarcinome testées, qu'elles soient ou non multipotentielles. Aucune autre souche tumorale, transformée ou non par un virus, ne s'est trouvée réagir avec ce sérum, ni aucun tissu différencié de l'animal adulte, à l'exception des cellules de la lignée germinale mâle qui réagissent à tous les stades de développement, du gonocyte au spermatozoïde (Artzł et al., 1973 ; Gachelin et al., 1976b). 
En outre, le sérum est actif sur les cellules embryonnaires précoces, avec une intensité accrue au cours du clivage, et après l'implantation jusqu'au jour 8 de l'embryogenèse (Buc-Caron, Condamine et Jacob, 1978). Les structures antigéniques ainsi mises en évidence paraissent donc caractéristiques d'un état embryonnaire indifférencié. Elles sont présentes dans d'autres espèces de Mammifères : l'Homme (Fellous ef al., 1974), le Rat, le Lapin, le Porc (R. Kemler, résultats non publiés).

La nature des déterminants antigéniques $\mathrm{F9}$ et des structures moléculaires qui les portent n'est pas encore connue. Un début de caractérisation a été effectué par Vitetta ef al. (1975) : à partir d'un extrait de cellules F9 radiomarquées, on peut, par action du sérum anti-F9 syngénique, obtenir un précipité dont les composants, soumis à une électrophorèse sur gel d'acrylamide dans des conditions dissociantes, ont des caractéristiques de migration qui rappellent celles des molécules $\mathrm{H} 2$. L'homologie F9-H2 que Vitetta et al. ont suggérée n'a cependant pas été vérifiée par la suite. En particulier, un sérum anti-H2 de Lapin qui réagit avec des antigènes $\mathrm{H} 2$ de n'importe quel haplotype, et avec les antigènes majeurs de transplantation d'autres Mammifères, l'Homme compris, ne réagit pas avec les cellules de tératocarcinome. S'il y a une homologie entre $\mathrm{F} 9$ et $\mathrm{H} 2$, il faut donc admettre qu'elle est plus lointaine que l'homologie entre, par exemple, les antigènes H2 et HLA (Morello ef al., 1978). Des résultats susceptibles d'une interprétation comparable ont été obtenus par Vitetta ef al. (1978).

II a été montré récemment que le sérum syngénique anti-F9 est complexe et comporte plusieurs classes d'immunoglobulines $\lg M, \lg G_{1}$ ef $\lg _{2}$ (Damonneville et al., 1979). Ces différentes classes reconnaissent probablement, non seulement des motifs antigéniques distincts, mais même des molécules différentes. En effet, certaines cellules (les spermatozoïdes par exemple) réagissent avec une classe d'immunoglobulines (les IgM) et non les autres. Il semble donc clair que « l'antigène F9 》 constitue en fait une famille composite dont le degré de complexité n'est cependant pas connu avec précision.

Une propriété de l'antigène F9 a retenu l'atrention : son absence apparente à la surface de cellules porteuses de certains haplotypes t. On sait que le locus $T$ est un segment du chromosome 17 pour lequel les souris sauvages présentent un haut degré de polymorphisme (Bennett, 1975 ; Lyon et al., 1979). Les haplotypes sauvages ont un ensemble complexe de propriétés, en particulier des effełs récessifs létaux répartis dans l'embryogenèse précoce (depuis le stade morula jusqu'à la formation du tube neural) et ils gouvernent, à la surface des spermatozoïdes, la présence d'antigènes spécifiques (Artzt ef Bennett, 1977). A la suite d'une observation d'Artzt, Bennett et Jacob (1974) selon laquelle les spermatozoïdes porteurs de l'haplotype fw32 $^{\text {(qui bloque }}$ le développement de l'embryon au stade morula) se comportent, dans des tests d'absorption, comme dépourvus d'antigène $F 9$, la même propriété a été retrouvée par Kemler et al. pour les morulae homozygotes $\uparrow^{\mathrm{w} 32} / \mathrm{t}^{\mathrm{w} 32}$ : parmi les morulae issues d'un croisement qui ségrège de tels homozygotes, une fraction ne réagit pas, dans des tests d'immunofluorescence indirecte avec le sérum syngénique anti-F9. En revanche, ces mêmes morulae réagissent avec le sérum anti-tw32. Formellement, les antigènes F9 et $\uparrow^{\mathrm{w} 32}$ se comportent comme des produits de gènes allèles, mais d'aułres interprétations sont possibles : défaut de membranes causé par l'haplotype † $^{\mathrm{w32}}$ ef empêchant l'intégration de $F 9$, mutations de gènes régulateurs portées par l'haplotype tw32 et interférant avec la synthèse de F9. Ces ambiguiltés ne pourront sans doute pas être levées 
avant que de nouveaux matériels cellulaires (des tératocarcinomes par exemple), porteurs d'haplotypes $t$, rendent possible l'obtention de sérums anti-t d'un maniement plus commode que ceux actuellement disponibles, tous obtenus par immunisation anti-sperme. L'isolement, par Kelly, Guénet et Condamine (1979) de lignées transformées par SV40 et homozygotes pour l'haplotype ${ }^{+w^{32}}$ (qui empêche la différenciation normale du mésoderme dans l'embryon de 7 jours) peut être un pas dans cette direction.

2) Sérum syngénique anti-PCC4.

PCC4 est une lignée de tératocarcinome provenant de la souris 129 , entretenue in vitro, qui réinjectée à l'animal, forme des tumeurs pluridifférenciées. C'est donc une souche multipotentielle. Par hyperimmunisation de la souris 129 , un sérum syngénique anti-PCC4 a été obtenu (Gachelin ef al., 1977) qui réagit avec les lignées multipotentielles et nullipotentielles (F9). Après absorption par les cellules $F 9$, le sérum continue à réagir avec $\mathrm{PCC} 4$, ce qui définit un nouvel antigène (ou groupe d'antigènes) propre à cette lignée. Recherché sur l'embryon précoce, cet antigène PCC4 n'a été trouvé qu'à partir de l'implantation du blastocyste sur les seules cellules de la masse cellulaire interne. Ce résultat illustre le fait que différentes lignées de tératocarcinome sont dans des états différents auxquels correspondent éventuellement des antigènes de surface différents. La chronologie d'apparition de l'antigène PCC4 est par ailleurs intéressante et peut être rapprochée de celle qui caractérise un antigène de type Forssman, trouvé sur les cellules de tératocarcinome et sur les blastocystes à l'aide d'un anticorps monoclonal anti-tératocarcinome (Stern et al., 1978 ; Willison et Stern, 1978).

3) Sérum xénogénique anti-F9.

A partir des immunoglobulines d'un sérum de Lapin anti-F9, des fragments monovalents ont été préparés dont l'action sur des embryons précoces de souris mis en culture est remarquable (Babinet ef al., 1977 ; Kemler ef al., 1977) : les divisions de clivage se poursuivent normalement mais au lieu que la morula forme une masse compacte à partir du stade 8 cellules, ses blastomères s'associent en une grappe lâche et la différenciation en blastocyste n'a pas lieu. L'effet est réversible : débarrassées des anticorps monovalents par lavage, les structures en grappe forment des morulas compactes puis des blastocystes qui, réimplantés dans l'utérus, se développent normalement. Les structures reconnues à la surface des blastomères par ces anticorps xénogéniques ne sont pas identifiées. Mais leur contrepartie existe aussi à la surface des cellules de tératocarcinome : la souche PCC3 (multipotentielle et capable de se différencier in vitro lorsque les cellules arrivent à confluence, Nicolas et al., 1976) voit ses cellules se dissocier sous l'effet des anticorps monovalents (J. F. Nicolas, communication personnelle).

4) Absence d'antigène $\mathrm{H}-2$ à la surface des cellules de tératocarcinome.

On a mentionné plus hauł qu'un sérum xénogénique de Lapin anti-H-2 ne réagissait pas avec les cellules de tératocarcinome (Morello ef al., 1978). Plus généralement, toutes les tentatives pour mettre en évidence la présence de $\mathrm{H}-2$ à la surface du tératocarcinome se sont soldées par la négative (Artzt et Jacob, 1974 ; Nicolas et al., 1975 ; Stern, Martin et Evans, 1976 ; Isa, 1976 ; revue dans Gachelin, 1978). 
Le problème de savoir si les antigènes $\mathrm{H}-2$ sont présents à la surface des cellules embryonnaires précoces a suscité beaucoup de travaux qui n'ont pas débouché sur une solution claire (voir Klein, 1975, pp. 333 à 337). Les ambiguïtés tiennent à la nature des réactifs sérologiques employés, aux techniques utilisées et à leurs différents degrés de sensibilité. Une source supplémentaire de confusion, moins remarquée en général, tient à ce que les embryons, à partir du stade blastocyste, sont des objets composites, dont tous les constituants n'ont peut-être pas les mêmes propriétés, en particulier pour ce qui est de H-2. La question : les cellules totipotentielles de l'embryon, entre le stade blastocyste ef la gastrulation, ont-elles les antigènes $\mathrm{H}-2$, n'a en général pas été spécifiquement posée. Toutefois, une expérience de Webb, Gall et Edelman (1977) conclut à la présence de $\mathrm{H}-2$ dans les cellules de la masse interne du blastocyste. $\mathrm{Si}$, dans ce dernier cas, la spécificité anti-H2 des réactifs utilisés ne vient pas à être remise en question, il faudrait alors admettre une différence importante entre cellules de tératocarcinome ef cellules embryonnaires totipotentielles. Une telle conclusion semble tout de même prématurée.

\section{E. - Sensibilité à l'égard des virus.}

Les cellules indifférenciées de tératocarcinome empêchent la multiplication de certains virus alors que celle-ci a lieu normalement dans les lignées différenciées qui dérivent du tératocarcinome. Il en est ainsi pour des virus de type $C$ (Peries ef al., 1977 ; Teich et al., 1977), des parvovirus (Miller, Ward et Ruddle, 1977), SV40 ef le virus du polyome (Swartzendruber, Friedrich ef Lehman, 1977 ; Boccara et Kelly, 1978). Pour d'autres virus, la multiplication a lieu aussi bien dans les cellules souches indifférenciées que dans les lignées différenciées dérivées. C'est le cas de l'adénovirus de type 2 (Kelly et Boccara, 1976), ou des virus de l'encéphalomyocardite, de Sindbis, de la vaccine et de la stomatite vésiculaire (Teich et al., 1977).

Le mécanisme du blocage qui affecte la multiplication de certains virus n'est pas connu avec précision mais on sait, dans le cas de SV40, que l'adsorption du virus, sa pénétration ef son transport jusqu'au noyau ont lieu de façon normale (Swartzendruber, Friedrich et Lehmann, 1977). Plus récemment, il a été montré que, dans la cellule F9, l'ARN messager de SV40 ne subit pas de maturation normale, par défaut d'épissage (《splicing 》) (Segal, Levine et Khoury, 1979). Toutefois, on ne sait rien de la généralité de ce mécanisme de blocage, dans le cas des autres virus et des autres lignées de tératocarcinome.

En revanche, les données sont moins claires en ce qui concerne la susceptibilité des cellules embryonnaires précoces aux virus. Peu de virus ont été examinés, et les résultats sont parfois contradictoires. Pour Jaenisch et Berns (1977), les embryons, avant implantation, n'autorisent pas la réplication de SV40, du virus du polyome, ou du virus leucémogène de Moloney. Pour Abramczuk et al. (1978), la culture en présence de SV40 d'embryons pris au stade 2 aboutit, après deux ou trois divisions, à la lyse des blastomères, par un mécanisme d'ailleurs inconnu. Quelques embryons survivent néanmoins jusqu'au stade blastocyste après infection par SV40; dans le cas de l'infection par le virus du polyome, beaucoup moins toxique, c'est la majorité. Dans les 2 cas, on peut mettre en évidence, dans les noyaux des cellules trophoblastiques, la présence d'antigènes viraux $T$ ef $V$. Ces antigènes n'apparaissent pas dans les noyaux 
de la masse cellulaire interne, ni lorsque les synthèses proféiques ont été inhibées par des drogues appropriées. Les cellules de la masse cellulaire interne pourraient donc avoir des propriétés voisines de celles du tératocarcinome, eu égard à la permissivité aux virus. Le stafut des cellules de la morula, totipotentielles, ne semble pas élucidé de façon définitive. Enfin, lorsque des embryons pris au stade œuf-cylindre sont cultivés in vitro et infectés par SV40, des signes de réplication virale apparaissent dans diverses catégories de cellules différenciées (cellules du sac vitellin, hématopoiétiques, ou du tube neural) (Solter, Biczysko et Koprowski, 1974). Bien que le comportement des cellules multipotentielles d'ectoderme embryonnaire présentes au début de ces cultures n'aił pas éfé étudié en détail, l'analogie que présente ce résultat avec l'apparition de la permissivité dans les cellules différenciées issues du tératocarcinome paraît évidente.

\section{III. - Retour des cellules de tératocarcinome à l'embryogenèse normale}

Au cours des quatre dernières années, la relation entre tératocarcinome et embryon, le fait que le premier reproduit, de façon anarchique, des processus de différenciation identiques à ceux du second, se sont trouvés illustrés de façon spectaculaire par l'obtention de souris chimériques ayant intégré dans leur organisme des cellules dérivées de tératocarcinome.

La technique utilisée consiste à injecter des cellules tératocarcinomateuses indifférenciées (donc tumorigènes) dans la cavité d'un blastocyste. L'opération est effectuée in vitro à l'aide d'un micromanipulateur. Le blastocyste est ensuite replacé dans un utérus d'une femelle convenablement préparée où il pourra continuer son développement. Il s'agit donc de l'adaptation d'une technique de Gardner (1968) qui a montré qu'on peut fabriquer des souris chimériques en injectant, dans la cavité d'un blastocyste de génotype a, la masse cellulaire interne provenant d'un blastocyste de génotype b.

Une première tentative due à Brinster (1974) utilisait des cellules dissociées de corps embryonnaires tératocarcinomateux. Ceux-ci comportent un cour de cellules indifférenciées tumorales et une couche périphérique de nature endodermique. Les cellules injeciées étaient apparemment prises au hasard et appartenaient à l'une ou l'autre classe. Sur 60 souriceaux provenant de blastocystes ayant reçu ce matériel, un possédait clairement des tissus ayant le génotype du téralocarcinome. Des résultats beaucoup plus démonstratifs ont été obtenus dans le laboratoire de B. Mintz (Mintz ef Illmensee, 1975 ; Illmensee et Mintz, 1976). Des corps embryonnaires d'un tératocarcinome d'origine $129 / \mathrm{Sv}$, on n'injecte cette fois que les cellules internes (indifférenciées). Dans une expérience où une seule cellule tumorale était injectée dans chaque blastocyste, 30 p. 100 des animaux produits comportaient des cellules de génotype $129 / \mathrm{Sv}$ dans un éventail très varié de tissus, y compris, dans quelques rares cas, dans la lignée germinale. Tous ces tissus chimériques étaient d'apparence normale et ne comportaient aucun signe de tumeur en voie de développement. Indépendamment de la signification de ces expériences pour ce qui concerne la nature de la cellule tératocarcinomateuse, elles rendent possibles l'incorporation in vivo de cellules por- 
teuses de mutations variées (obtenues à partir du tératocarcinome) et l'étude in vivo de l'effet de ces mutations. Deux exemples d'application de ce type ont déjà été fournis. Dans un cas, des souris chimériques porteuses de cellules dépourvues d'hypoxanthinephosphoribosyltransférase ont été produites (Dewey et al., 1977). Dans l'autre cas, des noyaux de cellules tératocarcinomateuses étaient fusionnés avec le cytoplasme de cellules de mélanome dont l'ADN mitochondrial porte une mutation qui confère la résistance au chloramphénicol. Les hybrides noyau-cytoplasme (《 cybrid») ainsi obtenus conservent la propriété du tératocarcinome de former des tumeurs différenciées, après injection sous-cutanée. Réinjectés dans des blastocystes, ces « cybrides» ont donné lieu à la naissance de souriceaux mosaïques. Il doit donc être possible d'étudier, à l'aide de cette technique, l'effet produit chez l'animal par des mutations, nucléaires ou cyłoplasmiques, sélectionnées sur des cellules en culture (Watanabe, Dewey ef Mintz, 1978). Un point de l'expérience de Watanabe doit être souligné. Alors que les souris provenant de tératocarcinome injecté dans des blastocystes (dans les conditions de Mintz ef ses collaborateurs) ne forment semble-t-il jamais de tumeurs, les placentas de certains fœetus disséqués au jour 12 ont livré des cellules de tératocarcinome que leurs propriétés tumorigènes ne distinguaient pas de la lignée de départ. Les implications possibles de cette observation seront examinées dans la section « Conclusions».

Une autre application a été tentée par Illmensee, Hoppe et Croce (1978) qui consistait à injecter dans des blastocystes des cellules de tératocarcinome ayant intégré un ou plusieurs chromosomes humains porteurs de marqueurs enzymatiques. L'expression d'enzymes humaines dans des tissus de souris a été obtenue dans quelques cas.

Dans un autre groupe d'expériences (Papaioannou ef al., 1975, 1978), l'aptitude de plusieurs lignées de tératocarcinome (entretenues in vitro pendant de nombreuses générations) à fournir des chimères après réinjection dans un blastocyste a été testée. La fréquence des animaux chimériques apparaît assez faible, de même que l'importance du composant d'origine tératocarcinomateuse dans les souris qui en comportent. En outre, la plupart des souris chimériques sont porteuses de tumeurs indifférenciées dès la naissance. Ces résultats sont donc assez différents de ceux obtenus par Mintz et ses collaborateurs. On peut supposer que le caryotype, jamais strictement normal, des lignées utilisées par Papaioannou et al. rend compte dans une certaine mesure de leur moindre aptitude à participer à une embryogenèse normale. II n'est pas exclu que d'autres facteurs entrent en jeu, qu'il reste à déterminer.

\section{IV. - Conclusions}

II est clair que des lignées indépendantes de tératocarcinome ont des propriétés différentes les unes des autres. Certaines souches sont multipotentielles, d'autres ont à peu près perdu toute aptitude à se différencier. Certaines se différencient in vitro, d'autres non. Les caryotypes présentent le plus souvent des écarts, particuliers pour chaque souche, par rapport à la diploïdie vraie. Tantôt un chromosome $X$ est inactivé, tantôt non. Des antigènes de surface, comme l'antigène F9, peuvent être exprimés arec plus ou moins d'intensité (G. Gachelin, communication personnelle). Ces diffé- 
rences n'empêchent pas qu'il existe, cependant, une similitude globale avec les cellules embryonnaires multipotentielles qu'on trouve depuis la masse cellulaire interne du blastocyste jusqu'à l'ectoderme embryonnaire de l'œuf-cylindre tardif : même ultrastructure simplifiée, mêmes marqueurs caractéristiques (antigène F9, haute activité en phosphatase alcaline, actine monomérique, etc.) et surtout, même aptitude à donner des dérivés différenciés multiples.

II est sûr que certaines au moins des différences qui séparent les lignées tératocarcinomateuses entre elles ont été acquises au cours de l'histoire de ces lignées, après qu'ait eu lieu la transformation tumorale. Par exemple, F9, lignée à peu près nullipotentielle et PCC3, lignée multipotentielle qui se différencie in vitro lorsque les cellules arrivent à confluence, ont toutes les deux été isolées à partir d'une même tumeur 129. Mais on peut se demander si ces différences ne tiennent pas aussi à ce que différents tératocarcinomes tirent éventuellement leur origine de cellules embryonnaires différentes, toutes situées cependant sur une même séquence de développement qui va de la masse cellulaire interne à l'ectoderme embryonnaire. Répondre à cette question est d'autant moins aisé qu'on ignore à peu près tout des différences qui séparent les cellules de ces deux constituants de l'embryon, ainsi que du nombre d'étapes qui seraient nécessaires pour aller de l'un à l'autre. Une étude de Moustafa et Brinster (1972) indique que des cellules d'un embryon de 5,5 jours sont capables, après injection dans un blastocyste de 3,5 jours, de participer à la formation d'embryons chimériques avec une efficacité comparable à celle des cellules de la masse interne, très supérieure à celle des cellules d'un embryon de 8 jours. Les cellules embryonnaires multipotentielles de 5,5 jours paraissent donc capables d'interargir avec celles du blastocyste, ce qui ne signifie pas, naturellement, qu'elles leur soient identiques. Ce type d'expérience mériterait d'être repris pour les cellules de l'ectoderme embryonnaire de 6 et 7 jours. Quoi qu'il en soit, deux schémas sont a priori possibles pour l'origine du tératocarcinome, soit que plusieurs types cellulaires, qui jalonneraient la progression de la masse cellulaire interne vers l'ectoderme de l'œuf-cylindre, puissent être soumis à la transformation tumorale, soit qu'un seul type soit susceptible de cette transformation. Le cas des cellules de la lignée germinale mâle qui, dans une ébauche gonadique de 12 ou 13 jours, sont tumorisables n'est pas nécessairement à part. Deux hypothèses ont été émises à leur sujet :

a) On peut postuler, en s'appuyant notamment sur des similitudes ultrastructurales, que ces cellules sont en fait identiques aux cellules de l'ectoderme embryonnaire de 6 ou 7 jours (Damjanov et Solter, 1974).

b) Ou bien, on peut imaginer que, dans un premier temps, ces cellules subissent une activation (par un processus qui pourrait être analogue à une parthénogenèse), ce qui les ferait s'engager dans une séquence de développement où elles afteindraient l'état sensible à la transformation tératocarcinomateuse qui semble caractériser les cellules de l'ectoderme embryonnaire ou, à tout le moins, une sous-population de ces cellules (Stevens, 1964 ; Mintz, Cronmiller et Custer, 1978).

Si l'identité de la cellule cible de cette transformation esł encore problématique, il peuł paraître vain de spéculer sur la nature de cet événement. On peut tout de même poser une alternative en termes très généraux. Ou bien la cellule tératocarcinomateuse dérive d'une cellule embryonnaire par un processus mutationnel, entendu au 
sens le plus large (pouvant comprendre, par exemple, la transposition d'un ou plusieurs éléments du génome, telle qu'elle semble avoir été mise en évidence dans certaines cellules eucaryotes (Cameron, Loh et Davis, 1979). Ou bien cette transformation est un processus purement épigénétique. L'opposition entre ces deux hypothèses n'est peut-être pas absolue. Par exemple, le processus qui aboutit à la formation d'une chaîne d'immunoglobuline implique un réarrangement de certaines séquences d'ADN et pourrait, par conséquent, être classé comme événement mutationnel (Hozumi et Tonegawa, 1976). Pourtant, il s'agit aussi d'un processus de différenciation, et, bien que son mécanisme soit encore obscur, on peut penser qu'il a toute chance d'être réglé de façon épigénétique.

On dispose de très peu d'éléments expérimentaux pour discuter le mécanisme qui donne naissance au tératocarcinome. La fréquence, estimée dans la première parfie, avec laquelle il apparaît dans les greffes de crêtes génitales (environ 1 p. 100) fait penser qu'il ne s'agit pas de mutations classiques, à moins d'imaginer un mécanisme particulier, telle la mise en action dans les conditions de la greffe, d'enzymes génératrices d'erreurs dans la réplication de l'ADN. II serait peut-être intéressant, de ce point de vue, d'éfudier l'action éventuelle de divers mutagènes sur les cellules embryonnaires précoces. De même, le retour de la cellule tératocarcinomateuse à l'embryogenèse normale semble s'effectuer, dans certaines conditions, avec une haute efficacité. Ce retour apporte une confirmation éclatante à l'idée que les dérivés différenciés du tératocarcinome sont identiques aux tissus adultes normaux (Pierce, 1961). Toutefois, l'argument de Kleinsmith ef Pierce (1964) selon lequel la producfion de fels dérivés, à partir des cellules souches, implique que celles-ci n'aient pas une origine mutationnelle, ne paraît pas absolument convaincant. On pourrait maintenir l'hypothèse de l'origine mutationnelle en supposant, par exemple, que dans les expériences de Mintz et Illmensee (1975), l'abolition du caractère tumoral provient, non pas de la réversion de ces mutations, mais de la mise en route d'un programme de différenciation au cours duquel le(s) gène(s) porteur(s) de ces mutations ne s'exprime(nt) plus (voir Hofnung, 1978). Un point demeure non éclairci dans ces expériences, celuide savoir si la «normalisation » des cellules tératocarcinomateuses résulte simplement de leur différenciation, telle qu'elle se produirait au cours de la formation d'une tumeur, ou si elle constitue la réponse à une «induction » du milieu embryonnaire normal. De ce point de vue, la récupération par Watanabe ef al. (1978) au jour 12 de l'embryogenèse, de cellules non « normalisées » au niveau du placenta permet de se demander si cette hypothétique «induction » ne caractérise pas certains tissus embryonnaires seulement. On voit par là que, tout autant qu'un modèle pour l'étude de la différenciation, le tératocarcinome offre d'utiles possibilités pour l'étude de la cancérogenèse.

Présenté au Colloque D. G. R. S. T. de Port Bail, 27 février-1er mars 1979.

Accepté en septembre 1979.

Remerciements. - Je remercie F. Jacob pour une lecture critique du manuscrit, ainsi que G. Gachelin, J. L. Guenet, R. Kemler, J. F. Nicolas et D. Paulin pour m'avoir permis d'utiliser certains de leurs résultats non publiés. Ce travail a bénéficié du sou- 
tien du Centre National de la Recherche Scientifique (LA 269), de la Délégation Générale à la Recherche Scientifique ef Technique, de I'Institution National de la Santé ef de la Recherche Médicale (76.4.311. AU) et de la Fondation André Meyer.

\section{Références}

ABRAMCZUK J., VORBRODT A., SOLTER D., KOPROWSKI H., 1978. Infection of mouse preimplantation embryos with simian virus 40 and polyoma virus. Proc. nat. Acad. Sci. USA, 75, 999-1003.

ADAMSON E. D., 1976. Isoenzyme transitions of creatine phosphokinase, aldolase and phosphoglycerate mutase in differentiating mouse cells. J. Embryol. exp. Morph., 35, 355-367.

ARTZT K., BENNETT D., 1977. Serological analysis of sperm of antigenically cross-reacting T/thaplotypes and their recombinants. Immunogenetics, 5, 97-107.

ARTZT K., BENNETT D., JACOB F., 1974. Primitive teratocarcinoma cells express a differentiation antigen specified by a gene at the T-locus in the mouse. Proc. nat. Acad. Sci. USA, 71, 811-814.

ARTZT K., DUBOIS P., BENNETT D., CONDAMINE H., BABINET C., JACOB F., 1973. Surface antigens common to mouse cleavage embryos and primitive teratocarcinoma cells in culture. Proc. nat. Acad. Sci. USA, 70, 2988-2992.

ARTZT K., JACOB F., 1974. Absence of serologically detectable H-2 on primitive teratocarcinoma cells in culture. Transplantation, 17, 632-634.

AVNER P. R., DOVE W. F., DUBOIS P., GAILLARD J. A., GUENET J. L., JACOB F., JAKOB H., SHEDLOVSKY A., 1978. The genetics of teratocarcinoma transplantation : tumor formation in allogeneic hosts by the embryonal carcinoma cell lines F9 and PCC3. Immunogenelics, 7, 103-115.

BABINET C., KEMLER R., DUBOIS P., JACOB F., 1977. Les fragments monovalents d'immunogiobulines de lapin anti-F9 empêchent la formation de blastocystes chez la souris. $C$. R. Acad. Sci. Paris, sér. D, 284, 1919-1922.

BENNETT D., 1975. The T-locus of the mouse. Cell, 6, 441-454.

BERNSTINE E. G., HOOPER M. L., GRANDCHAMP S., EPHRUSSI B., 1973. Alkaline phosphatase activity in mouse teratoma. Proc. nat. Acad. Sci. USA, 70, 3899-3903.

BOCCARA M., KELLY F., 1978. Susceptibility of teratocarcinoma cells to simian virus 40 and polyoma virus. Ann. Microbiol. (Inst. Pasteur), 129A, 227-238.

BOON T., VAN PEL A., 1978. Teratocarcinoma cell variants rejected by syngeneic mice : protection of mice immunized with these variants against other variants and against the original malignant cell line. Proc. nat. Acad. Sci. USA, 75, 1519-1523.

BOON T., KELLERMAN O., 1977. Rejection by syngeneic mice of cell variants obtained by mutagenesis of a malignant teratocarcinoma cell line. Proc. nat. Acad. Sci. USA, 74, 272-275.

BRINSTER R. L., 1974. The effect of cells transferred into the mouse blastocyst on subsequent development. J. exp. Med., 140, 1049-1056.

BUC-CARON M. H., CONDAMINE H., JACOB F., 1978. The presence of F9 antigen on the surface of mouse embryonic celts until day 8 of embryogenesis. J. Embryol. exp. Morph., 47, 149-160.

CALARCO P. G., BROWN E. H., 1969. An ultrastructural and cytological study of preimplantation development of the mouse. J. exp. Zool., 171, 253-283.

CAMERON J. R., LOH E. Y., DAVIS R. W., 1979. Evidence for transposition of dispersed repetitive DNA families in yeast. Cell, 16, 739-751.

CRONMILLER C., MINTZ B., 1978. Karyotypic normalcy and quasinormalcy of developmentally totipotent mouse teratocarcinoma cells. Develop. Biol., 67, 465-477.

DAMJANOV I., SOLTER D., 1974. Experimental teratoma. Curr. Top. Pathol., 59, 69-130.

DAMJANOV I., SOLTER D., 1975. Ultrastructure of murine teratocarcinomas, 209-220. In : SHERMAN M. I., SOLTER D. Teratomas and differentiation, Acad. Press, New York.

DAMJANOV I., KATIC V., STEVENS L. C., 1975. Ultrastructure of ovarian teratomas in LT mice. Z. Krebsforsch., 83, 261-267.

DAMJANOV I., CUTLER L. S., SOLTER D., 1977. Ultrastructural localization of membrane phosphatases in teratocarcinoma and early embryos. Amer. J. Pathol., 87, 297-310. 
DAMONNEVILLE M., MORELLO D., GACHELIN G., STANISLAVSKI M., 1979. Antibody response to embryonal carcinoma cells in syngeneic mice. Europ. J. Immunol. (in press).

DEWEY M. J., MARTIN D. W., MARTIN G. R., MINTZ B., 1977. Mosaic mice with teratocarcinomaderived mutant cells deficient in hypoxanthine-phosphoribosyltransferase. Proc. nat. Acad. Sci. USA, 74, 5564-5568.

DEWEY M. J., FILLER R., MINTZ B., 1978. Protein patterns of developmentally totipotent mouse feratocarcinoma cells and normal early embryo cells. Develop. Biol., 65, 171-182.

DIWAN S. B., STEVENS L. C., 1976. Development of teratomas from the ectoderm of mouse egg cylinders. J. nat. Cancer Inst., 57, 937-942.

EPPIG J. J., KOZAK L. P., EICHER E. M., STEVENS L. C., 1977. Ovarian teratomas in mice are derived from oocytes that have completed the first meiotic division. Nature, 269, 517-518.

FELLOUS M., GACHELIN G., BUC-CARON M. H., DUBOIS P., JACOB F., 1974 . Similar location of an early embryonic antigen on mouse and man spermatozoa. Develop. Biol., 41, 331-337.

FLETCHER L., RIDER C. L., TAYLOR C. B., ADAMSON E. D., LUKA B. M., GRAHAM C. F., 1978. Enolase isoenzymes as markers of differentiation in teratocarcinoma cells and normal tissues of mouse. Develop. Biol., 65, 462-475.

GACHELIN G., 1976. Le tératocarcinome expérimental de la souris : un système modèle pour l'étude des relations entre antigènes de surface cellulaires ef différenciation embryonnaire. Bull. Cancer, 63, 95-110.

GACHELIN G., 1978. The cell surface antigens of mouse embryonal carcinoma cells. Biochim. biophys. Acta, 516, 27-60.

GACHELIN G., BUC-CARON M. H., LIS H., SHARON N., 1976a. Saccharides on teratocarcinoma cell plasma membranes : their investigation with radioactively labeled lectin. Biochim. biophys. Acto, 436, 825-832.

GACHELIN G., FELLOUS M., GUENET J. L., JACOB F., 1976b. Developmental expression of an early embryonic antigen common to mouse spermatozoa and cleavage embryos and to human spermatozoa : its expression during spermatogenesis. Develop. Biol., 50, 310. 320.

GACHELIN G., KEMLER R., KELLY F., JACOB F., 1977. PCC4, a new cell surface antigen common to multipotential embryonal carcinoma cells, spermatozoa and mouse early embryos. Develop. Biol., 57, 199-209.

GARDNER R. L., 1968. Mouse chimaeras obtained by the injection of cells into the blastocyst. Nature, 220, 596-597.

GARTLER S. M., ANDINA R. J., 1976. Mammalian X-chromosome inactivation. Adv. Hum. Gen., 7, 99-140.

GRAHAM C., 1977. Teratocarcinoma cells and normal mouse embryogenesis, 315-394. In SHERMAN M. T. Concepts in mammalian embryogenesis, M. I. T. Press, Cambridge, Mass.

HANDYSIDE A. H., JOHNSON M. H., 1978. Temporal and spatial patterns of the synthesis of tissue specific polypeptides in the preimplantation mouse embryo. J. Embryol. exp. Morph., 44, 191-199.

HASS P. E., WADA H. G., HERMAN M. M., SUSSMAN H. H., 1979. Alkaline phosphatase of mouse teratoma stem cells : immunochemical and struciural evidence for its identity as a somatic gene product. Proc. nat. Acad. Sci. USA, 76, 1164-1168.

HOFNUNG M. J., 1978. Introduction à l'étude des relations entre mutagenèse et cancérogenèse. Biochimie, 60, 1151-1171.

HOGAN B. L. M., 1977. Teratocarcinoma cells as a model for mammalian development. Int. Rev. Biochem. Biochemistry of Differentiation II, 15, 333-376. PAUL J. éd. Univ. Park Press, Baltimore.

HOZUMI N., TONEGAWA S., 1976. Evidence for somatic rearrangement of immunoglobulin genes coding for variable and constant regions. Proc. nat. Acad. Sci. USA, 73, 3628-3632.

ILES S. A., EVANS E. P., 1977. Karyotype analysis of teratocarcinomas and embryoid bodies of C3H mice. J. Embryol. exp. Morphoi., 38, 77-92.

ILLMENSEE K., MINTZ B., 1976. Totipotency and normal differentiation of single teratocarcinoma cells cloned by injection into blastocysts. Proc. nat. Acad. Sci. USA, 73, 549-553.

ILLMENSEE K., HOPPE P. C., CROCE C. M., 1978. Chimeric mice derived from human-mouse hybrid cells. Proc. nat. Acod. Sci. USA, 75, 1914-1918. 
ISA A. M., 1976. Lack of demonstrable H2 antigens on the surface of teratocarcinoma $402 \mathrm{AX}$ of the mouse maintained in vivo. Transplantation, 21, 195-198.

JACOB F., 1977. Mouse teratocarcinoma and embryonic antigens. Immunol. Rev., 33, 3-22.

JAENISCH R., BERNS A., 1977. Tumor virus expression during mammalian embryogenesis, 267-315. In SHERMAN M. T., Concepts in mammalian embryogenesis, M. I. T. Press, Cambridge, Mass.

JAMI J., RITZ E., 1974. Multipotentiality of single cells of transplantable teratocarcinomas derived from mouse embryo grafts. J. nat. Cancer Inst., 52, 1547-1552.

KELLY F., BOCCARA M., 1976. Susceptibility of teratocarcinoma cells to adenovirus type 2. Nature, 262, 409-411.

KELLY F., GUÉNET J. L., CONDAMINE H., 1979. Karyologically identified homozygous tw18 embryos : extra uterine growth properties and transformation by SV40. Cell. 16, 919927.

KEMLER R., BABINET C., CONDAMINE H., GACHELIN G., GUÉNET J. L., JACOB F., 1976. Embryonal carcinoma antigen and the T/t locus of the mouse. Proc. nat. Acad. Sci. USA, 73, 4080-4084.

KEMLER R., BABINET C., EISEN H., JACOB F., 1977. Surface antigen in early differentiation. Proc. nat. Acad. Sci. USA, 74, 4449-4452.

KLEIN J., 1975. Biology of the mouse histocompatibility-2 complex. Springer-Verlag, Berlin.

KLEINSMITH L. J., PIERCE G. B. Jr., 1964. Multipotentiality of single embryonal carcinoma cells. Cancer Res., 24, 1544-1552.

LEVINSON J., GOODFELLOW P., VADEBONCOEUR M., MCDEVITT H., 1978. Identification of stage-specific polypeptides synthesized during murine preimplantation development. Proc. nat. Acad. Sci. USA, 75, 3332-3336.

LYON M. F., EVANS E. P., JARVIS S. E., SAYERS I., 1979. t-haplotypes of the mouse may involve a change in intercalary DNA. Nature, 279, 38-42.

MARTIN G. R., 1975. Teratocarcinomas as a model system for the study of embryogenesis and neoplasia. Cell. 5, 229-243.

MARTIN G. R., EVANS M. J., 1975. Differentiation of clonal lines of teratocarcinoma cells : formation of embryoid bodies in vitro. Proc. nat. Acad. Sci. USA, 72, 1441-1445.

MARTIN G., EPSTEIN C. J., TRAVIS B., TUCKER G., YATZIV S., MARTIN D. W. Jr., CLIFT S., COHEN S., 1978. X-chromosome inactivation during differentiation of female feratocarcinome stem cells in vitro. Nafure, 271, 329-333.

MARTIN G. R., SMITH S., EPSTEIN C. J., 1978. Protein synthetic patterns in teratocarcinoma stem cells and mouse embryos at early stages of development. Develop. Biol., 66, 8-16.

MCBURNEY M. W., 1976. Clonal lines of teratocarcinoma cells in vitro : differentiation and cytogenetic characteristics. J. Cell Physiol., 89, 441-455.

MCBURNEY M. W., ADAMSON E. D., 1976. Studies on the activity of the $X$ chromosomes in female teratocarcinoma cells in culture. Cell. 9, 57-70.

MILLER R. A., WARD D. C., RUDDLE F. H., 1977. Embryonal carcinoma cells (and their somatic cell hybrids) are resistant to infection by the murine parvovirus MVM which does infect other teratocarcinoma derived cell lines. J. Cell Physiol., 91, 393-402.

MINTZ B., CRONMILLER C., 1978. Normal blood cells of anemic genotype in teratocarcinomaderived mosaic mice Proc. nat. Acad. Sci. USA, 75, 6247-6251.

MINTZ B., ILLMENSEE K., 1975. Normal genetically mosaic mice produced from malignant teratocarcinoma cells. Proc. nat. Acad. Sci. USA, 72, 3585-3589.

MINTZ B., RUSSELL E. S., 1957. Gene-induced embryological modifications of primordial germ cells in the mouse. J. exp. Zool., 134, 207-237.

MINTZ B., CRONMILLER C., CUSTER R. P., 1978. Somatic cell origin of teratocarcinomas. Proc. nat. Acad. Sci. USA, 75, 2834-2838.

MORELLO D., GACHELIN G., DUBOIS P., TANIGAKI N., PRESSMAN D., JACOB F., 1978. Absence of reaction of a xenogeneic anti-H2 serum with mouse embryonal carcinoma cells. Transplantation, 26, 119-125.

MOUSTAFA L. A., BRINSTER R. L., 1972. Induced chimaerism by transplanting embryonic cells into mouse blasfocysts. J. exp. Zool., 181, 193-202.

MURAMATSU T., GACHELIN G., NICOLAS J. F., CONDAMINE H., JAKOB H., JACOB F., 1978. Carbohydrate structure and cell differentiation : unique properties of fucosyl-glycopeptides isolated from embryonal carcinoma cells. Proc. nat. Acad. Sci. USA, 75, 2315-2319. 
MURAMATSU T., CONDAMINE H., GACHELIN G., JACOB F., 1979. Changes in fucosyl-glycopeptides during early post implantation embryogenesis in the mouse. J. Embryol. exp. Morph. (sous presse).

NICOLAS J. F., DUBOIS P., JAKOB H., GAILLARD J,, JACOB F., 1975. Tératocarcinome de la souris : différenciation en culture d'une lignée de cellules primitives à potentialités multiples. Ann. Microbiol. (Inst. Pasteur), 126A, 3-22.

NICOLAS J. F., AVNER P., GAILLARD J., GUÉNET J. L., JAKOB H., JACOB F., 1976. Cell lines derived from teratocarcinomas. Cancer Res., 36, 4224-4231.

O'FARRELL P. H., 1975. High resolution two-dimensional electrophoresis of proteins. J. biol. Chem., $250,4007-4021$.

PAPAIOANNOU V. E., McBURNEY M. W., GARDNER R. L., EVANS M. J., 1975 . Fate of teratocarcinoma cells injected into early mouse embryos. Nafure, 258, 70-73.

PAPAIOANNOU V. E., GARDNER R. L., BURNEY M. W., BABINET C., EVANS M. J., 1978. Participation of cultured teratocarcinoma cells in mouse embryogenesis. J. Embryol. exp. Morphol., 44, 93-104.

PAULIN D., NICOLAS J. F., YANIV M., JACOB F., WEBER K., OSBORN M., 1978. Actin and tubulin in teratocarcinoma cells. Develop. Biol., 66, 488-499.

PERIES J., DEBONS-GUILLEMIN M. C., CANIVET M., EMANOIL-RAVICOVITCH R., TAVITIAN A., BOIRON A., 1977. Studies on murine C-type virus multiplication in mouse teratocarcinoma cell lines. Nouv. Rev. fr. Hematol. Blood Cells. 18, 383-390.

PIERCE G. B., 1961. Teratocarcinomas, a problem in developmental biology, 119-137. In 4th Can. Cancer Conf., 4, Acad. Press, New York.

PIERCE G. B. Jr., BEALS T. F., 1964. The ultrastructure of primordial germinal cells and fetal testes and of embryonal carcinoma cells in mice. Cancer Res., 24, 1553-1567.

PREHN R. T., 1977. Immunostimulation of the lymphodependent phase of neoplastic growth. J. nat. Cancer Inst., 59, 1043-1049.

SEGAL J., LEVINE A. J., KHOURY G., 1979. Evidence for non-spliced SV40 RNA in undifferentiated murine teratocarcinoma stem cells. Nature (in press).

SHERMAN M. I., MILLER R. A., 1978. Embryonal carcinoma celis can cifferentiate into endodermlike cells. Develop. Biol., 63, 27-34.

SOLTER D., SKREB N., DAMJANOV I., 1970. Extra uterine growth of mouse egg-cylinders results in malignant teratoma. Nature, 227, 503-504.

SOLTER D., BICZYSKO W., KOPROWSKI H., 1974. Host-virus relationship at the embryonic level, 3-30. In KUNSTAK E., MARAMOROSCH K. Viruses, evolution and cancer. Acad. Press, New York.

SOLTER D., BICZYSKO W., PIENKOWSKI M., KOPROWSKI H., 1974. Ultrastructure of mouse egg cylinders developped in vifro. Anat. Rec., 180, 263-280.

SOLTER D., DAMJANOV I., KOPROWSKI H., 1975. Embryo-derived teratoma : a model system in developmental and tumor biology, 243-264. In BALLS M. WILD A. E., The early development of mammals. Cambridge Univ. Press.

SOLTER D., DAMJANOV I., 1979. Teratocarcinomas rarely develop from embryos transplanted into athymic mice. Noture, 278, 554-555.

SORIANO L., PAULIN D., 1978. Alkaline deoxyribonuclease activity in mouse teratocarcinoma cells : variation of enzyme levels during differentiation. Biochim. biophys. Res. Comm., 83, 406-413.

SPIEGELMAN M., BENNETT D., 1973. A light- and electron-microscopy study of primordial germ cells in the early mouse embryo. J. Embryol. exp. Morph., 30, 97-118.

STERN P. L., MARTIN G. R., EVANS M. J., 1976. Cell surface antigens of clonal teratocarcinoma cells at various stages of differentiation. Cell, 6, 455-465.

STERN P. L., WILLISON K. R., LENNOX E., GALFRE G., MILSTEIN C., SECHER D., ZIEGLER A., SPRINGER T., 1978. Monoclonal antibodies as probes for differentiation and tumor-associated antigens : a Forssman specificity on teratocarcinoma stem cells. Cell, 14, 775-783.

STEVENS L. C., 1959. Embryology of testicular teratomas in strain 129 mice. J. nat. Cancer Inst., 23, $1249-1295$.

STEVENS L. C., 1962. Testicular teratomas in fetal mice. J. nat. Cancer Inst., 28, 247-268.

STEVENS L. C., 1964. Experimental production of testicular teratomas in mice. Proc. nat. Acad. Sci. USA, 52, 654-661. 
STEVENS L. C., 1967a. The biology of teratomas. Adv. Morphogenesis, 6, 1-31.

STEVENS L. C., 1967b. Origin of testicular teratomas from primordial germ cells in mice. J. nat. Cancer Inst., 38, 549-552.

STEVENS L. C., 1970a. Experimental production of testicular teratomas in mice of strains 129, A/He, and their F1 hybrids. J. nat. Cancer Inst., 44, 923-929.

STEVENS L. C., 1970b. The development of transplantable teratocarcinomas from intratesticular grafts of pre- and post-implantation mouse embryos. Develop. Biol., 21, 364-382.

STEVENS L. C., 1973. A new inbred subline of mice (129/ter Sv) with a high incidence of spontaneous congenital testicular teratomas. J. nat. Cancer Inst., 50, 235-242.

STEVENS L. C., LITTLE C. C., 1954. Spontaneous testicular teratomas in an inbred strain of mice. Proc. nat. Acad. Sci. USA, 40, 1080-1087.

STEVENS L. C., MACKENSEN J. A., 1961. Genetic and environmental influences on teratocarcinogenesis in mice. J. nat. Cancer Inst., 27, 443-453.

STEVENS L. C., VARNUM D. S., 1974. The development of teratomas trom parthenogenetically activated ovarian mouse eggs. Develop. Biol., 37, 369-380.

SWARTZENDRUBER D. E., SCOTT CRAM L., LEHMANN J. M., 1976. Microfluorometric analysis of DNA content changes in a murine teratocarcinoma. Cancer Res., 36, 1894-1899.

SWARTZENDRUBER D. E., FRIEDRICH T. E., LEHMANN J. M., 1977. Resistance of teratocarcinoma stem cells to infection with simian virus 40 : early events. J. Cell Physiol., 93, 25-30.

TEICH N. M., WEISS R. A., MARTIN G. R., LOWY D. R., 1977. Virus infection of murine teratocarcinoma stem cell lines. Cell, 12, 973-982.

THEILER K., 1972. The house mouse. Berlin, Springer-Verlag.

VAN BLERKOM J., BARTON S. C., JOHNSON M. H., 1976. Molecular differentiation in the preimplantation mouse embryo. Nature, 259, 319-321.

VITETTA E. S., ARTZT K., BENNETT D., BOYSE E. A., JACOB F., 1975. Structural similarities between a product of the $T / t$ locus isolated from sperm and teratoma cells and $\mathrm{H}-2$ antigens isolated from splenocytes. Proc. nat. Acad. Sci. USA, 72, 3215-3219.

VITETTA E. S., COOK R., ARTZT K., POULIK M. D., UHR J. W., 1978. Further structural studies on the F9 (T/t) antigen(s). Europ. J. Immunol., 7, 826-829.

WADA H. G., VANDENBERG S. R., SUSSMAN H. A., GROVE W. E., HERMAN M. M., 1976. Characterization of 2 different alkaline phosphatases in mouse teratoma : partial purification, electrophoretic and histochemical studies. Cell, 9, 37-44.

WATANABE T., DEWEY M. J., MINTZ B., 1978. Teratocarcinoma cells as vehicles for introducing specific mutant mitochondrial genes into mice. Proc. nat. Acad. Sci. USA, 75, 5113-5117.

WEBB C. G., GALL W. E., EDELMAN G. M., 1977. Synthesis and distribution of H-2 antigens in preimplantation mouse embryos. J. exp. Med., 146, 923-932.

WILLISON K. R., STERN P. L., 1978. Expression of a Forssman antigenic specificity in the preimplantation mouse embryo. Cell, 14, 785-793. 